\title{
Impact of Sports Celebrity Endorsements on the Purchase Intentions of Pakistani Youth
}

\begin{abstract}
Farah Naz Baig
Dr. Kamran Siddiqui

Abstract

To anybody interested in sports and marketing, the concept of celebrity endorsment is not a new one. In recent decades, sport marketing has emerged as an independent area where companies separate themselves from their competitors by developing associations with the sporting heroes. In this study, the dynamics, as have emerged in the recent past, will be analyzed and implications for both sports and marketing evaluated. This study is an exploratory study and for this study data from 127 university students was collected. Data was collected with the help of surveys and was further analyzed with the help of a) descriptive statistics b) Confirmatory factor analysis c) Regression Analysis. The study focuses on the university students and limited geographical region of Pakistan for the purpose of data collection. The research concludes that celebrity endorsements could have an impact on the attitude towards the brand but it does not necessarily create motivations to purchase. This study provides deep insights for the marketers in terms of celebrity endorsements for their brands. The research will be a valuable addition in proliferation of knowledge on the subject area.
\end{abstract}

Keywords: Consumerbehavior, celebrity endorsements, sports.

\section{Introduction}

The concept of celebrity endorsement is not new. Boorstin (1961) defines a person's popularity as the celebrity factor. Celebrities always attracted marketing professional's attention because they help increase the sales of the brand because they tend to transport their positive image to the brand (McCracken, 1989). Schlecht (2003) explains a celebrity as a person who is widely known and enjoys great lifestyle. Celebrities can come from various sectors-films, theatre, sports, and numerous other walks of life. This paper specifically focuses on the usage of sports persons as celebrity endorsers.

A sport is considered to be an informal activity (Morgan \& Summers, 2005). Sports marketing can be defined as how companies separate themselves from the competitors by developing associations with the sporting heroes (Schlossberg, 1996). From the consumer perspective attending sports events is an experience. The consumption leads to intangible (i.e. psychological) rather than tangible benefits i.e. monetary benefits (Gladden \& Funck, 2002). From the organization's perspective sports marketing is a well accepted promotional tool (Nufer \& Buhler, 2010) that helps in increasing the purchase likelihood, generating positive word of mouth which eventually leads to greater market share (Kim et al., 2011). Bee and Havitz (2010) claim that sustaining relationships with the sports consumers is far better than acquiring new customers. Furthermore, Lardinoit \& Derbaix (2001) indicate that increase in sports sponsorship expenditure is due to the increasing clutter on television, direct marketing and print media. Therefore,

Farah Naz Baig is lecturer at the Institute of Business Administration (IBA), Karachi, farahnazbaig@hotmail.com Dr. Kamran Siddiqui is Dean at Suffa Business School (DHA), Karachi, kamran_siddiqui@hotmail.com

\begin{tabular}{llll|l}
\hline Journal of Independent Studies and Research - MSSE & Volume 10 & Number 1 & January 2012 & 23
\end{tabular} 
sports sponsorships help in reaching large and diverse sets of audiences at a single point in time - for instance 37 billion television viewers were reached in the 1998 FIFA World Cup. Kim and Trail (2010) explain that sports marketing help organizations develop better relationship with their partners because it integrates processes, people, operations and marketing capabilities.

Moreover, Ko et al. (2008) explain the other important reason behind the increase in sports sponsorships which is that majority of the corporate sponsors have shown their satisfaction with their relationships with sports leagues, teams and organizations. The sporting industry worldwide has grown exponentially (Schaaf, 1995). Estimated size of the sports industry is $\$ 422$ billion in the US and annual company spending on sports advertising is $\$ 27.8$ billion in 2011 (Sports Recreation and Leisure Market Research , 2011). Soccer is the world's most popular game followed by cricket, basketball, baseball, rugby union, field hockey, volley ball, ice hockey, American football and rugby league (Doley, 2009). "In 2009, the sports retail industry experienced $\$ 11.5$ billion in sales, not including more than $\$ 1$ billion from licensed video games" (Fusfeld, 2010). Various sports celebrities are used in order to endorse various product categories and brands for instance Tiger Woods, Maria Sharapova, Roger Federer, Sachin Tendulkar, Wasim Akram, who are well known sports celebrities are seen endorsing different brands. These endorsements earn the players billions of dollars outside the field. The results of the celebrity endorsements are usually positive and generate the require word of mouth. However, in case of any negative publicity of the celebrity, the consequences are disastrous for the brand. Ching (2010), reports that Tiger Wood's endorsement has had a positive impact on Nike's products. Similarly when Michael Jordan, a very well known basket ball celebrity, endorsed Nike the results were incredibly positive for the brand.

\section{Literature Review}

Celebrity is defined as any individual who enjoys public recognition (McCracken, 1989). Consumers have well defined schemas for such individuals (Speck, Schumann, \& Thomson, 1988). Sports celebrities are individuals who benefit from great recognition in their respective sports and mostly acts as role models for many young people (Bush, Martin, \& Bush, 2004). Various researches have been conducted which explain the importance of using sports celebrity such as the research conducted by McCracken (1989) who explained the transference of meanings from the celebrity to the product and further onwards from the product to the end consumer.The transference of meaning could be both postive such as the announcements of using celebrities have had positive results on stock (Agrawal \& Kamakura, 1995)or negative for instance Amos and Holmes (2008) suggest that any negative information related to the celebrity could have negative consequences for the campaign. Another study indicates the impact of multiple product endorsements by the same celebrity which indicates that the overall attitude towards the brand becomes less favorable and the credibility and trustworthiness of the celebrity also declines. (Tripp, Jensen, \& Carlson, 1994). There could be various types of endorsers (Friedman and Friedman, 1979) such as expert or corporation. Ohanian (1990) divides the credibility of the endorser into three constructs: namely attractiveness, trustworthiness and expertise. According to the source credibility model (Lafferty et al, 2002) the message effectiveness is dependent on the source credibility which is defined as the source attractiveness, expertise and trustworthiness (Lafferty, 2002). Various researches have

\footnotetext{
24 January 2012 $\quad$ Volume $10 \quad$ Number $1 \quad$ Journal of Independent Studies and Research - MSSE
} 
been conducted which depict the impact of the source credibility on the attitude and behavior of respondents (Jones, Sinclair, \& Courneya, 2003; Grewal, Gotlieb, \& Marmorstein, 1994; Petty \& Cacioppo, 1984; Gotlieb, Schlacter, \& St. Louis, 1992; Pornpitakpan, 2004 ). Furthermore, Cohen and Golden (1972) and Kahle and Homer (1985) suggest the importance of physical attractiveness of the source on creating the desired level of persuasion. Liu and Brook (2011) explained that the attractiveness of the endorser affects the Chinese consumers purchase intention. Furthermore, Spry et al. (2011) claim that even a reasonably low credibility endorser has helped in brand building. Various reseaches were conducted indicating the impact of attractiveness of sports celebrity on the attitude of people (Caballero and Pride,1984; Chaiken, 1979; Mills \& Harvey, 1972). Kamins(1990) found that for an attractiveness related product, the attractiveness of the celebrity has greater impact as compred to non-attractive on the product.

\subsection{Celebrity Endorsement and Product Fit}

Various researches have been conducted that indicate the importance of celebrity product fit such as Kamins \& Gupta (1994); Kelman (1961); Till, Stanley, \& Priluck (2008); Lynch \& Schuler (1994); Hakimi, Abedniya, \& Nokhbeh Zaeim (2011).Till and Busler (1998) have suggested the importance of having a fit between the celebrity and the product. However, the results in their research indicated that the celebrity backing has a positive impact on the predisposition rather than the purchase intention. The fit relates more to the fact whether the sports celebrity is endorsing sports products or non-sports products, the endorsements of non-sports products raises questions about the effectiveness of the endorsement(Braunstein-Minkove, Zhang, \& Trail, 2011). Bower and Landreth (2001) claim that the match between the endoerser and the product amplifies the perceptions about the prodcut/brand being endorsed. Furthermore, Ang et al. (2006), studied the personality transfer from the celebrity to the product. However, they assert that the tranference of personality is not very effective in case the brand has a very strong name.It was further known that there could also be reverse impact (i.e. the transference of image from the brand to the celebrity). The negative perceptions about the brand can negatively influence the celeberity (Doss, 2007). On the other hand, Silvera \& Austad (2004), describe that the individuals who have less than a college degree tend to get more influenced by celebrity endorsements.

\subsection{Research Gap}

Various researches have been conducted related to sports marketing; which deal with the impact of sports sponsorship, usage of sports celebrities in advertisements etcetera. However, no such research has been conducted in Pakistan to determine the perceptions of people regarding sports celebrities and their impact on the behavioral motivation of the people towards the brands/products endorsed.

\section{Research Methodology}

\subsection{Problem statement}

There various sports such as hockey, cricket, football, basket ball, volley ball, polo, table tennis, tennis, squash, athletics that are played in Pakistan. Athletes from various 
sports are taken to endorse different product categories. The reason for this research is to find out the overall perceptions of respondents regarding the sports celebrities and to identify the impact the sports celebrity endorsements on the purchase intentions and brand loyalty.

\subsection{Research Questions}

a) To determine the perceptions of people towards the sports celebrities endorsing the product?

b) To determine the impact of sports celebrity endorsement on the purchase intentions?

\subsection{Research Approach}

Researches could be qualitative or quantitative in nature or both. For the purpose of this exploratory research both qualitative and quantitative approaches were used. For the qualitative aspect focus group was conducted and for quantitative, a survey was conducted. The research was conducted in three phases; the first phase comprised of secondary research. In the second phase a focus group was conducted and in the third phase, a survey approach was used in order to confirm responses received from focus group.

\subsubsection{Secondary Research}

Various researches have been conducted in the area of celebrity endorsements. For the purpose of understanding the topic, various research articles pertaining to celebrity endorsements and sports celebrity endorsements were analyzed. The understanding of the topic helped the researcher in developing the literature review and to develop semi-structured questionnaire for the research.

\subsubsection{Focus Group}

A very important tool to gain insights is through focus groups. One focus group was conducted for this research. The respondents comprised of university students in their final BBA program. The researcher acted as the moderator for the focus group. The primary reason for selecting students for the purpose of this research is because various social sciences researches use students as their respondents and for topics like celebrities and sports, they tend to possess immense knowledge.

Key findings of the focus group are given below:

a) Entertainment: something that relaxes, that excites (boys said that sports excites), in case of any political event or hype then watch news.

b) Celebrity is defined as a self-made person, somebody who is glorious, who is a legend.

c) In Pakistan celebrities are more from sports and internationally or are usually from the show business. There are two or three sectors from which we have celebrities. The first category being show biz, second sports and third probably politics. The kind of following that political people have cannot really be called as celebrity popularity.

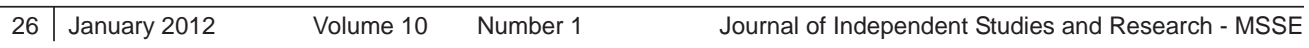


d) The characteristics of an ideal sports celebrity are charisma, personality, educational background, stats to back (stats means the number of games that you have played), humility, responsible acting. They should also stay within their limits.

e) Whether or not celebrity endorsement will have an impact or not depends on whether the sports celebrity is using product that he is endorsing. Also whether the product is related to his profession.

f) However, if a celebrity is endorsing a certain brand then you will give it a second thought, but you may not necessarily buy it. Celebrity endorsements do create the buzz.

\subsubsection{Survey}

In order to confirm the responses obtained from the focus group, a survey research was conducted at the Institute of Business Administration, Karachi. Total one hundred and fifty questionnaires were filled through self administered procedure. Systematic sampling technique was used for the survey. A list of all classes was obtained through the administration and the classes were selected randomly for the research. Some of the questionnaires were rejected due to incomplete information.

\subsection{Research Instrument}

The research instrument used for the purpose of this research consists of open ended, close ended questions and likert scales. The three factors that make up the construct source credibility namely attractiveness, trustworthiness, and expertise are taken by a validated research instrument developed by Ohanian (1990). Another important construct, behavior, a validated scale developed by McMullan (2005) was used. The attitude construct was developed based on the analysis literature and focus group.

\subsection{Instrument Validity}

Determining the validity of the questionnaire is crucial. For the purpose of this research, the constructs, source credibility (comprising of trustworthiness, attractiveness and expertise) and impact on brand were checked with the help of validated scales developed by Ohanian (1990) and McMullan (2005) respectively. However, the validity of the construct attitude was checked with the help of agreement among various researchers. Finally, the questionnaire was pre- tested before actually conducting the survey.

\subsection{Reliability}

Zikmund (2002) describes reliability as the consistency of results. The following table indicates the reliability for the constructs used in this study.

\begin{tabular}{lcc}
\hline Construct & Number of Items & A \\
\hline Attractiveness & 4 & 0.72 \\
Trustworthiness & 5 & 0.83 \\
Expertise & 5 & 0.82 \\
Attitude & 4 & 0.69 \\
Impact on Brand & 6 & 0.82 \\
\hline
\end{tabular}

\begin{tabular}{llll|l}
\hline Journal of Independent Studies and Research - MSSE & Volume 10 & Number 1 & January 2012 & 27
\end{tabular}


The Cronbach's alpha signifies the internal consistency (Craonbach,1951) the values generally lie between $0-1$. The tables given above indicate suitable alpha values for the research as in social sciences the minimum suitable value is considered to be 0.5

\subsection{Conceptual Model}

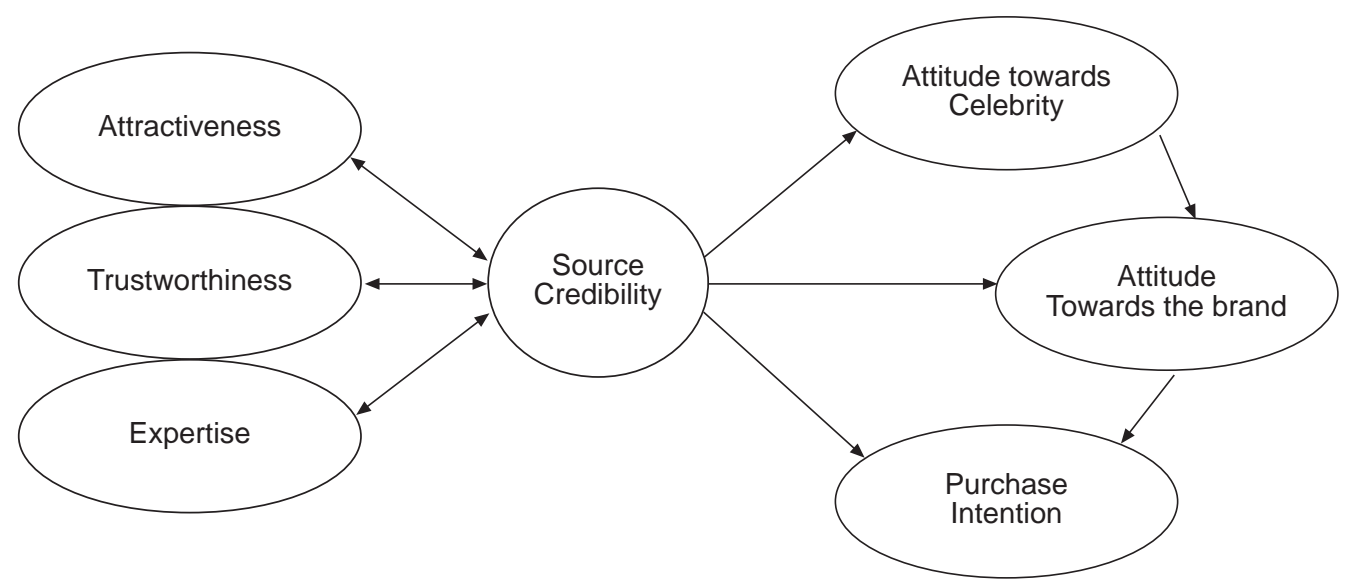

The conceptual model indicates that the three factors making source credibility as given by Ohanian (1990) will have an impact on the attitude towards celebrity which in turn will lead to some positive or negative attitude towards the brand which in turn will affect the purchase behavior. In certain circumstances, such as the low involvement situation, the consumers might directly engage in a certain behavior towards the product as a result of the source/celebrity credibility.

\subsection{Hypotheses}

\section{Hypothesis 1:}

Ho: Source credibility does not impact the attitude towards the source.

$\mathrm{H} 1$ : Source credibility has an impact on the attitude towards the source.

\section{Hypothesis 2:}

Ho: Source credibility does not impact the behavior towards the endorsed brand. $\mathrm{H} 1$ : Source credibility impacts the behavior towards the endorsed brand.

\section{Hypothesis 3:}

Ho: The attitude towards the source does not have impact on the behavior towards the brand.

$\mathrm{H} 1$ : The attitude towards the source has an impact on the behavior towards the brand.

\begin{tabular}{l|lll}
\hline 28 & January 2012 & Volume 10 & Number $1 \quad$ Journal of Independent Studies and Research - MSSE
\end{tabular}




\section{Analysis}

The analysis for this research was conducted with the help of SPSS 18. The data was analyzed based on descriptive statistics, confirmatory factor analysis, second order factor analysis, regression and correlation.

\subsection{Descriptives}

Table 1:

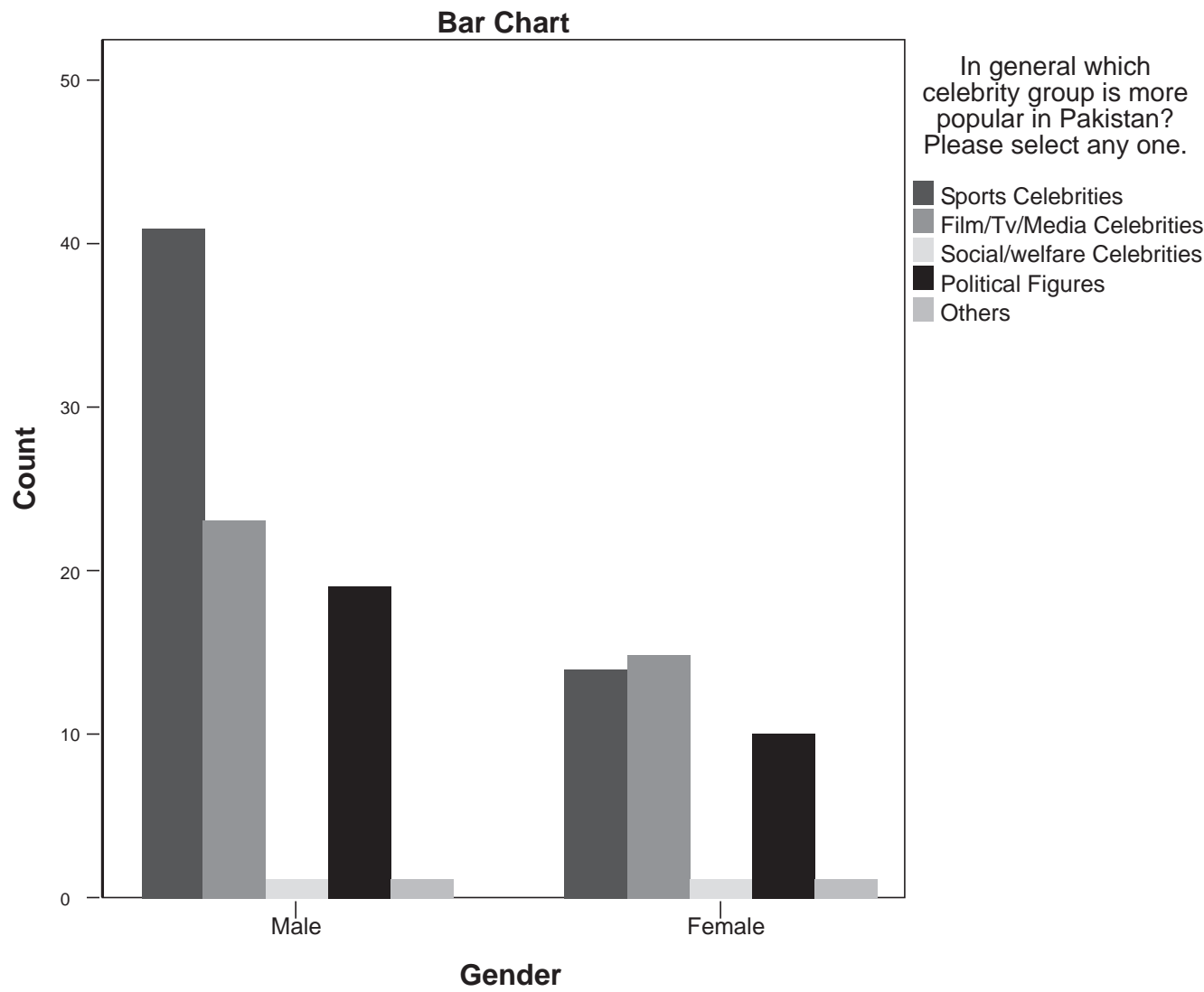

As indicated by the table, majority of the males responded that the sports sector has more celebrities as compared to females who reported that film industry has more celebrities. This somehow indicates the interest level of both genders in different sectors. Males are more into sports and they have more information related to sports as compared to females. 
Table 2:

In general which celebrity group is more popular in Pakistan ? Please select any one.

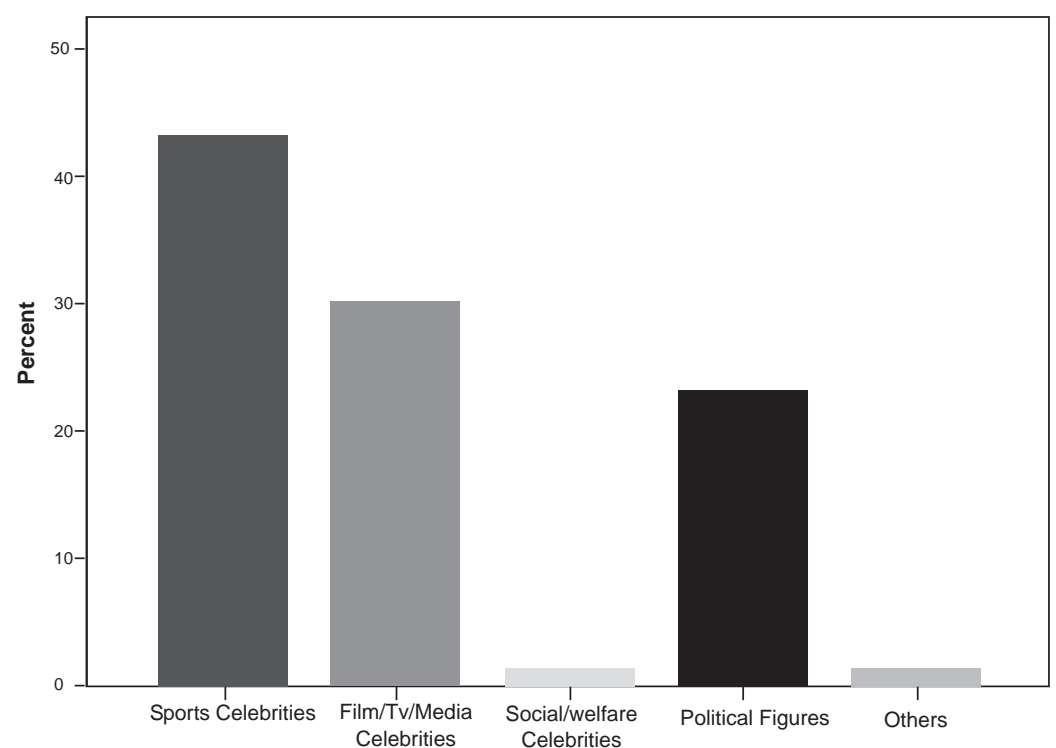

Table 2 indicates that the majority of people consider sports celebrities as a more popular group in Pakistan wheras TV/media celebrities and political figures being second and third respectively.

Table 3:

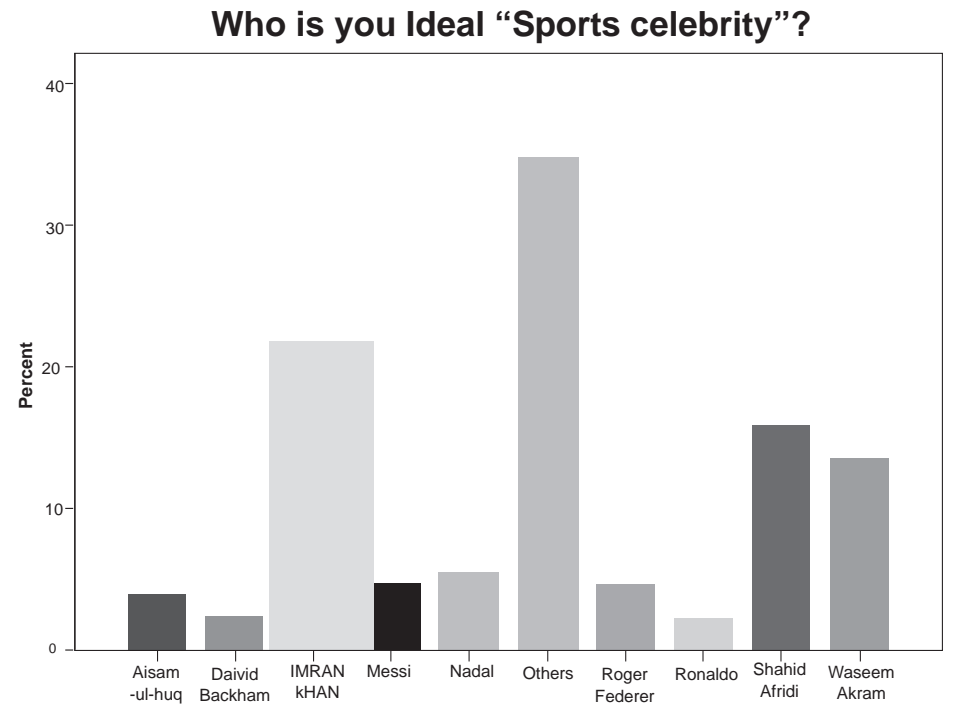

Table 3 indicates a difference in opinion in terms of ideal sports celebrity. However, there seems to be a consistency in response when it comes to Shahid Afridi and

30 January 2012 $\quad$ Volume $10 \quad$ Number $1 \quad$ Journal of Independent Studies and Research - MSSE 
Waseem Akram in case of ideal sports celebrity. Other players from tennis and football have also been highlighted which indicates the popularity of sports amongst the respondents.

Table 4:

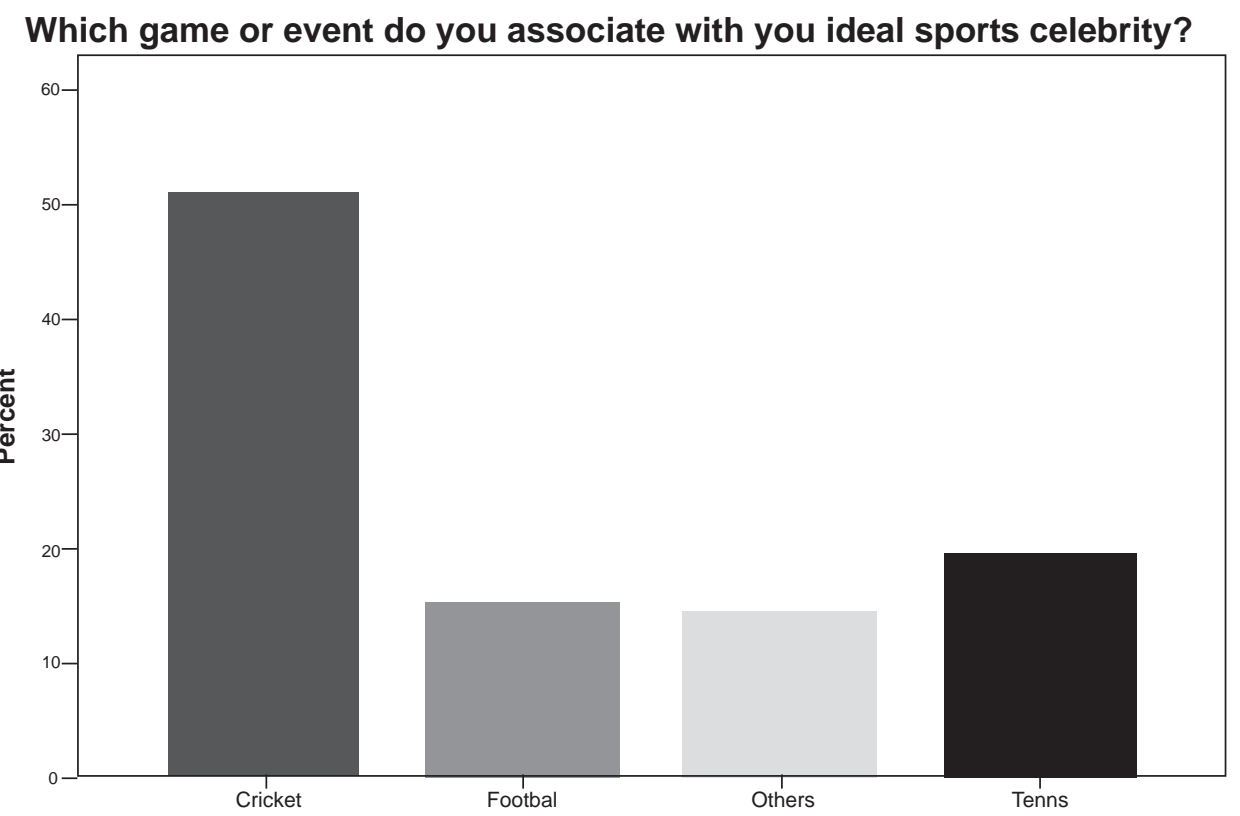

Table 4 confirms the fact that for majority of the respondents, Shahid Afridi and Waseem Akram were the favorite players and both these players were associated with cricket. Tennis is at number two which could be because another Pakistani tennis player Aisam ul- Haqq got international recognition which contributed to the success of this sport.

\subsection{Confirmatory Factor Analysis}

A confirmatory factor analysis was done for five factors, namely attractiveness, trustworthiness, expertise, attitude and impact on behavior. The criteria used for evaluation was as follows:

a) Each item loading on one factor should have a loading value of more than 0.3

b) There should be at least 3 items loading on one factor. 
Table5: Attractive

\begin{tabular}{ll} 
Eigen Value & 2.23 \\
\hline Variance explained & 55.74 \\
$\mathrm{M}$ & 3.41 \\
$\mathrm{SD}$ & .70 \\
Alpha & .72 \\
\hline Items & Factor Loadings \\
Attractive & .817 \\
Beautiful & .821 \\
Sexy & .785 \\
Elegant & .522 \\
\hline Extraction Method: Principal Component Analysis KMO= .74
\end{tabular}

Initially five items were known for attractiveness namely attractive, beautiful, sexy, classy and elegant. Eventually, four items were loaded and the item classy was discarded. This means that the final definition of attractiveness is beautiful, attractive, sexy and elegant. KMO of .74 indicates that the sample size is sufficient.

\section{Table 6: Trustworthiness}

\begin{tabular}{ll} 
Eigen Value & 3.04 \\
\hline Variance explained & 60.81 \\
Mean & 3.78 \\
Standard Deviation & 0.704 \\
Alpha & 0.83 \\
\hline Items & Factor Loadings \\
Trustworthy & .864 \\
Sincere & .842 \\
Reliable & .812 \\
Honest & .732 \\
Dependable & .625 \\
\hline Extraction Method: Principal Component Analysis KMO= .732
\end{tabular}

Five items were known for trustworthiness namely trustworthy, sincere, reliable, honest, and dependable. All five items were loaded on the trustworthy factor. This means that the final definition of attractiveness is beautiful, attractive, sexy and elegant. KMO of .73 indicates that the sample size is sufficient. 
Table 7: Expertise

\begin{tabular}{ll} 
Eigen Value & 2.9 \\
\hline Variance explained & 57.99 \\
Mean & 4.17 \\
Standard Deviation & 0.62 \\
Alpha & 0.82 \\
\hline Items & Factor Loadings \\
Expert & 814 \\
Experienced & .778 \\
Knowledgeable & .702 \\
Qualified & .760 \\
Skilled & .750
\end{tabular}

\section{Extraction Method: Principal Component Analysis KMO $=.822$}

Initially five items were known for expertise namely expert, experienced, knowledgeable, qualified and skilled. Eventually, all five items were loaded on the expert factor. This means that the final definition of attractiveness is beautiful, attractive, sexy and elegant. $\mathrm{KMO}$ of .82 indicates that the sample size is sufficient.

The table given below indicates that all three factors are loading on one factor which is the source credibility, which means that all are measuring the same concept.

Table 8 FA: Source Credibility (N-127)

First Order Factors Attractive Trust

Eigen Value

Var ex

$\mathrm{M}$

SD

KMO

C Alpha

Items

Attrt

Beau

Sexy

Elegant

Trust

Sincere

Reliable

Honest

Depend

Expert

Expercd

Qualifd

Skilled
$2.23 \quad 3.04$

$\begin{array}{ll}55.74 & 60.81\end{array}$

$3.41 \quad 3.78$

$\begin{array}{ll}0.7 & 0.704\end{array}$

$0.74 \quad 0.732$

$0.72 \quad 0.83$
Knowdg
Expert

$$
2.9
$$

57.99

4.17

0.62

0.822

0.82

Factor Loadings

0.82

0.82

0.78

0.52

0.86

0.84

0.81

0.73

0.63

0.81

0.78

0.70

0.76

0.75
Second Order Factor Source Credibility
1.75
58.34
3.79
0.514
0.61
0.63

0.65

0.81

Journal of Independent Studies and Research - MSSE

Volume 10 
Table 9: Attitude towards celebrity

\begin{tabular}{ll}
\hline Eigen Value & 2.17 \\
\hline Variance explained & 54.4 \\
Mean & 3.36 \\
Standard Deviation & 0.76 \\
Alpha & 0.69 \\
\hline Items & Factor Loading \\
Regularly watch his/her games in playground. & .751 \\
Try to meet him/her more often & .524 \\
Talk positive things about him/her & .809 \\
Would be watching him/her in future & .828 \\
\hline Extraction Method: Principal Component Analysis KMO = .702
\end{tabular}

Initially six items were known for attitude. Eventually, four items were loaded, namely regularly watch his/her games in playground, try to meet him/her more often, talk positive things about him/her, would be watching him/her in future. KMO of .70 indicates that the sample size is sufficient.

Table 10: Attitude towards the brand

\begin{tabular}{lc}
\hline Eigen Value & 2.91 \\
\hline Variance explained & 58.41 \\
Mean & 2.97 \\
Standard Deviation & 0.72 \\
Alpha & 0.82 \\
\hline Items & Factor Loadings \\
Say positive things about the product or brand to other people. & .71 \\
Recommend products or services to someone who seeks my advice & .87 \\
Encourage friends and relatives to buy certain products & .84 \\
Continue to do business with a certain company & .69 \\
Pay more for products & .69 \\
\hline Extraction Method: Principal Component Analysis KMO= & .77 \\
\hline
\end{tabular}

Initially five items were known for attitude towards the brand. Eventually, all five items were loaded. KMO of .77 indicates that the sample size is sufficient.

\begin{tabular}{|c|c|c|c|c|}
\hline \multicolumn{2}{|r|}{, } & Volume 10 & Number 1 & Journal of Independent Studies and Research - MSSE \\
\hline
\end{tabular}




\subsection{Regression}

Table 11: Regression Analysis

\begin{tabular}{|l|l|r|r|r|r|}
\hline \multicolumn{7}{|c|}{ Summary of Regression Analysis } \\
\hline Dependent Variable & Independent Variable & Beta & $\mathbf{R}^{\mathbf{2}}$ & \multicolumn{1}{|c|}{ Adjusted $\mathbf{R}^{\mathbf{2}}$} & $\mathbf{F}$ \\
\hline 1 Attitude towards celebrity & Source Credibility & 0.491 & 0.241 & 0.235 & 39.3 \\
\hline 2 Attitude towards brand & Attitude towards celebrity & 0.37 & 0.137 & 0.13 & 19.6 \\
\hline 3 Purchase Intention & Attitude towards brand & 0.472 & 0.223 & 0.217 & 35.59 \\
\hline & Source Credibility & & & & \\
\hline & Attitude towards the brand & & & & \\
\hline
\end{tabular}

Table 11 shows three different regression analyses done. The first one indicates independent factor source credibility (which comprised of three constructs, namely attractiveness, trustworthiness and expertise) and dependent variable attitude towards celebrity. The value of adjusted $R^{2}$ of .235 suggests that source credibility can explain a good amount of variation in attitude towards celebrity and the ? value suggests that these constructs are directly related to one another. In the second situation, the attitude toward the celebrity does not have a significant impact on the attitude towards the brand because the value shown by adjusted $R^{2}$ is .13. Regression analysis with independent variables like source credibility, attitude towards the source and attitude towards the brand were used to identify the impact on purchase intentions, only attitude towards the brands showed significant impact on the purchase intentions because the value for adjusted $R^{2} .217$ means that purchase intentions could be influenced by numerous outside factors other than the celebrity endorsements.

\subsection{Hypothesis Testing}

The following are the results of study:

\section{Hypothesis 1:}

Ho: Source credibility does not impact the attitude towards the source.

$\mathrm{H} 1$ : Source credibility has an impact on the attitude towards the source

Decision Rule: The regression analysis shows the adjusted $\mathrm{R}^{2}$ value of .235. Therefore, sufficient evidence exists to state that source credibility has a positive impact on the attitude towards the source. This means that individuals who believe that the endorser is attractive, trustworthy and credible will have a positive predisposition towards the celebrity. Therefore the null hypothesis is rejected and we accept the alternative hypothesis which means that source credibility has an impact on the attitude towards the source.

\section{Hypothesis 2:}

Ho: Source credibility does not impact the behavior towards the endorsed brand.

$\mathrm{H} 1$ : Source credibility impacts the behavior towards the endorsed brand. 
Decision Rule: The regression analysis shows the adjusted $R^{2}$ value of .105 . Therefore, sufficient evidence does not exist to state that source credibility has a significant positive impact on the behavior towards the brand. This means that individuals who believe that the endorser is attractive, trustworthy and credible will probably not be inclined towards having positive conations towards the brand. Therefore, we accept the null hypothesis which is that source credibility does not impact the behavior towards the endorsed brand.

\section{Hypothesis 3:}

Ho: The attitude towards the source does not have impact on the behavior towards the brand.

$\mathrm{H} 1$ : The attitude towards the source has an impact on the behavior towards the brand.

Decision Rule: The regression analysis shows the adjusted $\mathrm{R}^{2}$ value of .105. Therefore, sufficient evidence does not exist to state that source credibility has a significant positive impact on the behavior towards the brand. This means that individuals who believe that the endorser is attractive, trustworthy and credible will probably not be inclined towards having positive attitude towards the brand. Therefore, we accept the null hypothesis which is source credibility does not impact the behavior towards the endorsed brand.

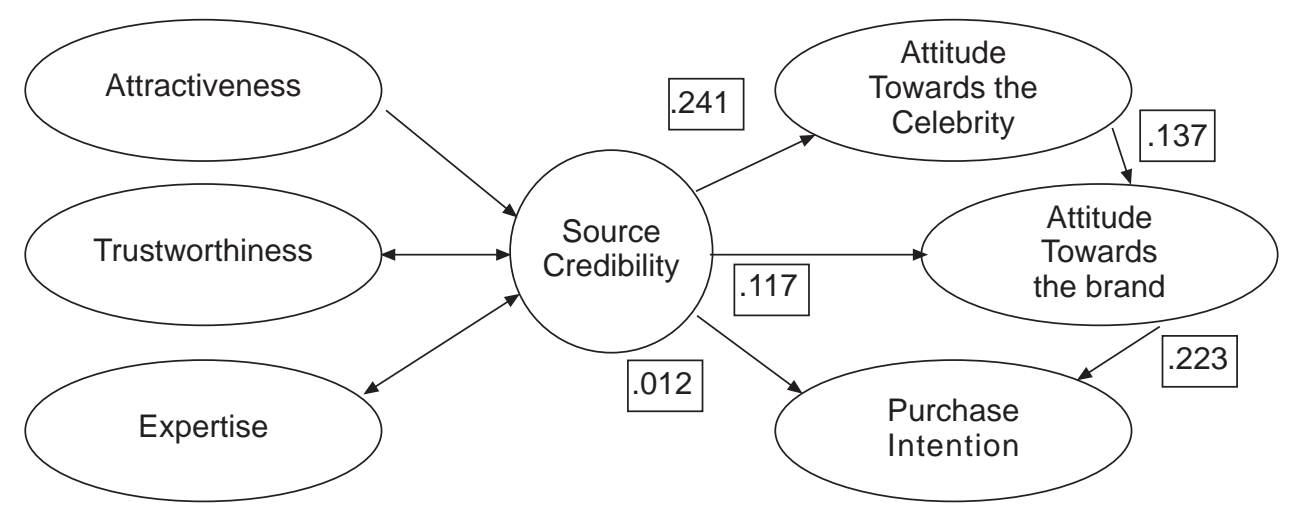

\section{Findings and Discussion}

The basic reason behind conducting this research was to determine whether or not the celebrity endorsement has any impact on the attitude or behavior towards the brand being endorsed. As indicated in the focus group, the endorsements might lead the consumer to recall the brand but it will not create significant behavioral impact in terms of purchasing the product, generating positive word of mouth about the product or creating or maintaining brand loyalty. It was also further substantiated by the regression analysis done that there exist a spurious relationship between the source/celebrity credibility and the behavioral impact on the brand. However, overall the positive regression results means the source credibility is explaining significant variation in the attitude towards the celebrity indicates that the more trustworthy, credible and expert the source is considered the more positively the people will be towards celebrity. However, this will not have any significant impact on the behavioral motivation of people which contradicts 
with the previous researches done such as Agrawal \& Kamakura (1995); Cohen and Golden (1972); Kahle and Homer (1985); Liu and Brook (2011); Spry et al., (2011);Caballero and pride (1984); Chaiken (1979); Mills \& Harvey (1972); Kamins (1990). However, this research supports the previous research conducted by Till and Busler (1998), which indicates that celebrity endorsements can lead to positive attitude towards the brand but it may not necessarily lead the person into buying the product. Another important finding of this study was the fact that positive or negative attitude towards the celebrity might lead to positive or negative attitude towards the brand which is in congruence with the studies conducted by Agrawal and Kamakura (1995) and McCracken (1989). When the regression analysis with independent variables like source credibility, attitude towards the source and attitude towards the brand were used to identify the impact on purchase intentions, only attitude towards the brands showed significant impact on the purchase intentions which means that purchase intentions could be influenced by several external factors other than celebrity endorsements.

\subsection{Conclusion}

Through this research, it can be concluded that the trustworthiness, attractiveness and expertise can lead to credibility of the celebrity, which in turn could affect the attitude towards the brand that the endorser is endorsing. However, this research does indicate any positive results in terms of motivation of people to purchase the product when it come to celebrity endorsement. The results indicate that the predisposition towards the brand have an impact on purchase intentions which could mean that these attitudes could be developed not just because of celebrity endorsements but because of various other external factors such as the performance of the product, the extent to which the product is meeting the expectations of people in terms of psychological or functional satisfactions.

\subsection{Importance of the Study}

This research adds insights for the marketers in terms of the usage of celebrities for the product endorsements, the usage of celebrities might lead to brand recall and positive/ negative transference of meanings from the celebrity to the brand/product. However, if they want to induce trial of the newly developed product or sustain market share, they need to take a step further by ensuring that they are able to come up to the expectations of the actual/ potential consumers.

\subsection{Need for Further Research}

This study provides deep insights for the marketers in terms of usage of celebrity endorsements in the campaigns and which sector has the greatest popularity so that endorsers could be used from that sector. However, further research needs to be conducted whether product-celebrity fit creates a positive impact on the purchase intentions in the Pakistani context. Also whether the sports celebrities have greater impact in cases of low involvement or the high involvement products? Also, it could also be determined what personalities or income groups could be positively influenced by celebrities. 


\subsection{Limitation}

The greatest drawback was the fact that survey was conducted only in Karachi. Conducting the survey in other parts of the country as well would help us gauge the perceptions of people regarding the celebrity and their willingness to purchase the products endorsed by them. Another important drawback of this study was the usage of students as the respondents. 


\section{References}

Agrawal, J. \& Kamakura, W. A. 1995, 'The Economic Worth of Celebrity Endorsers: An Event Study Analysis,' Journal of Marketing ,Vol. 59, No. 3, pp. 56-62.

Amos, C. \& Holmes, G. 2008, 'Exploring the Relationship between Celebrity Endorser Effects and Advertising Effectiveness: A Quantitative Synthesis of Effect Size,' International Journal of Advertising, Vol. 27, No. 2, pp. 209-234.

Ang, L. \& Dubelaar, C. 2006, 'Explaining Celebrity Match-up: Co-Activation Theory Of Dominant Support,' www.acrwebsite.org/Vol.umes/ap07/12968.pdf

Ang, L. Dubelaar, C. \& Kamakura, W. 2006, 'Changing Brand Personality through Celebrity Endorsement,' ANZMAC, pp. 1679-1686.

Bower, A. B. \& Landreth, S. 2001. 'Is Beauty Best? Highly versus Normally Attractive Models in Advertising,' Journal of Advertising, Vol. 30, No. 1, pp. 1-12.

Braunstein-Minkove, J. R., Zhang, J. J. \& Trail, G. T. 2011, 'Athlete Endorser Effectiveness: Model Development and Analysis,' Sport, Business and Management: An International Journal, Vol. 11, pp. 93-114.

Caballero, M. J. \& Pride, W. M. 1984, 'Selected Effects of Salesperson Sex and Attractiveness in Direct Mail Advertisements,' The Journal of Marketing, Vol. 48, pp. 94-100.

Bee, C. C. \& Havitz, M. E. 2010, 'Exploring the Relationship between Involvement, Fan Attraction, Psychological Commitment and Behavioural Loyalty in a Sports Spectator Context,' International Journal of Sports Marketing and Sponsorship, pp. 140-157.

Ching, K., Derdenger, T. \& Srinivasan, K. 2011, 'Economic Value of Celebrity Endorsement: Tiger Woods' Impact on Sales of Nike Golf Balls, (June 10), pp. 1-53.

Chaiken, S. 1979, 'Communicator physical attractiveness and persuasion,' Journal of Personality and Social Psychology, Vol. 37, No. 8, pp. 1387-1397.

Colley, A., Ermana, E. \& Milling, L. V. 2005, 'Age and Gender Differences in Young People's Perceptions of Sport Participants,' Journal of Applied Social Psychology, Vol. 35, pp. 1440-1454.

Doss, S. 2007, 'The Transference of Brand Attitude: The Effect on the Celebrity Endorser,' Journal of Management and Marketing Research, Vol. 7, pp. 1-11

Erdogan, Z. B. 1999, 'Celebrity Endorsement: A Literature Review,' Journal of Marketing Management, Vol. 15, No. 4, pp. 291-314.

Fusfeld, A. 2010, 'Sports Merchandise Sales are Strong Heading into Holiday Season,' www.businessinsider.com/sports-merchandise-sales-are-strong-heading-into-holidayseason-2010-11 
Gladden, J. M. \& Funck, D. C. 2002, 'Developing an Understanding of Brand Associations in Team Sports: Empirical Evidence from Consumers of Professional Sports,' Journal of Sports Management, Vol. 15, No. 1, pp. 54-81.

Goldsmith, R. E., Lafferty, B. A. \& Newell, S. J. 2000, 'The Impact of Corporate Credibility and Celebrity Credibility on Consumer Reaction to Advertisements and Brands,' Journal of Advertising, Vol. 29, No. 3, pp. 43-54.

Gotlieb, J. B., Schlacter, J. L. \& St. Louis, R. D. 1992, 'Consumer decision making: A model of the effects of involvement, source credibility, and location on the size of the price difference required to induce consumers to change suppliers,' Psychology and Marketing, Vol. 9, No. 3, pp. 191-208.

Grewal, D., Gotlieb, J. \& Marmorstein, H. 1994, 'The Moderating Effects of Message Framing and Source Credibility on the Price-Perceived Risk Relationship,' Journal of Consumer Research, Vol. 21, No. 1, pp. 145-153 .

Hakimi, B. Y., Abedniya, A. \& Nokhbeh Zaeim, M. 2011, 'Investigate the Impact of Celebrity Endorsement on Brand Image,' European Journal of Scientific Research, Vol. 58, No. 1, pp. 116-132.

Hsu, C.K. \& Mcdonald, D. 2002, ' An examination on multiple celebrity endorsers in advertising,' Journal of Product \& Brand Management, Vol. 11, No. 1, pp. 19-29.

Kim, Y. K. \& Trail, G. 2010, 'Constraints and Motivators: A New Model to Explain Sport Consumer Behavior,' Journal of Sports Management, Vol. 24, No. 2, pp. 190-210.

Kim, Y. K., Trail, G. T., Woo, B. \& Zhang, J. 2011, 'Sports consumer-team relationship quality: development and psychometric evaluation of a scale,' International Journal of Sports Marketing and Sponsorships, Vol. 12, No. 3, pp. 254-271.

Klaus, N. \& Bailey, A. A. 2009, 'Celebrity Endorsements: An Examination of Gender and Consumers' Attitudes,' American Journal of Business, Vol. 23, No. 2, pp. 53-62.

Ko, Y. J., kim, K., Claussen, C. L. \& Kim, T. H. 2008, 'The effects of sport involvement, sponsor awareness and corporate image on intention to purchase sponsors' products,' International Journal of Sports Marketing and Sponsorships, Vol. 9, pp. 79-94.

Jones, L. W., Sinclair, R. C. \& Courneya, K. S. 2003, 'The Effects of Source Credibility and Message Framing on Exercise Intentions, Behaviors, and Attitudes: An Integration of the Elaboration Likelihood Model and Prospect Theory,' Journal of Applied Social Psychology, Vol. 33, No. 1, pp. 179-196.

Kahle, L. R. \& Homer, P. M. 1985, 'Physical Attractiveness of the Celebrity Endorser: A Social Adaptation Perspective,' Journal of Consumer Research, Vol. 11, No. 4, pp. 954-961.

Kamins, M. A. 1990, 'An Investigation into the "Match-up" Hypothesis in Celebrity Advertising: When Beauty May Be Only Skin Deep,' Journal of Advertising, Vol. 19, No. 1, pp. 4-13.

\begin{tabular}{l|lll}
\hline 40 & January 2012 & Volume 10 & Number $1 \quad$ Journal of Independent Studies and Research - MSSE
\end{tabular}


Kamins, M. A. \& Gupta, K. 1994, 'Congruence between spokesperson and product type: A matchup hypothesis perspective,' Psychology and Marketing, Vol. 11, No. 6, pp. 569586.

Kamins, M. A., Brand, M. J., Hoake, S. A. \& Moe, J. C. 1989, 'Two-Sided versus OneSided Celebrity Endorsements: The Impact on Advertising Effectiveness and Credibility,' Journal of Advertising, Vol. 18, No. 2, pp. 4-10.

Lafferty, B. A. 2002, 'The Dual Credibility Model: The Influence of Corporate and Endorser Credibility on Attitudes and Purchase Intentions,' Journal of Marketing Theory and Practice, Vol. 10, No. 3, pp. 1-13

Lynch, J. \& Schuler, D. 1994, 'The matchup effect of spokesperson and product congruency: A schema theory interpretation,' Psychology and Marketing, Vol. 11, No. 5, pp. 417-445.

Lear, K. E., Runyan, R. C. \& Whitaker, W. H. 2009, 'Sports celebrity endorsements in retail products advertising,' International Journal of Retail and Distribution Management, Vol. 37, No. 4, pp. 308-321.

Liu, M. T. \& Brook, J. L. 2011, 'Selecting a female athlete endorser in China: The effect of attractiveness, match-up, and consumer gender difference,' European Journal of Marketing, Vol. 45, No. 7, pp. 1214-1235.

McCracken, G. 1989, 'Who is the Celebrity Endorser? Cultural Foundations of the Endorsement Process,' Journal of Consumer Research, Vol.16, pp. 310-321.

Mills, J. \& Harvey, J. 1972, 'Opinion change as a function of when information about the communicator is received and whether he is attractive or expert?' Journal of Personality and Social Psychology, Vol. 39, No. 2, pp. 52-55.

Misra, S. \& Beatty, S. E. 2002, 'Celebrity spokesperson and brand congruence: An assessment of recall and affect,' Journal of Business Research, Vol. 21, No. 2, pp. 159-173 .

Nufer, G. \& Bühler, A. 2010, 'How effective is the sponsorship of global sports events?A comparison of the FIFA World Cups in 2006 and 1998,' International Journal of Sports Marketing and Sponsorship, pp. 303-319.

Ohanian, R. 1990., 'Construction and Validation of a Scale to Measure Celebrity Endorsers' Perceived Expertise, Trustworthiness, and Attractiveness,' Journal of Advertising, Vol. 19, No. 3, pp. 39-52.

Petty, R. E. \& Cacioppo, J. T. 1984, 'Source Factors and the Elaboration Likelihood Model of Persuasion,' Advances in Consumer Research, Vol. 11, pp. 668-672.

Pornpitakpan, C. 2004, 'The Persuasiveness of Source Credibility: A Critical Review of Five Decades' Evidence,' Journal of Applied Social Psychology, Vol. 34, No. 2, pp. 243-281. 
Seno, D. \& Lukas, B. A. 2007, 'The Equity Effect of Product Endorsement by Celebrities: A Conceptual Framework from a Co-branding Perspective,' European Journal of Marketing, Vol. 41, No. 1/2, pp. 121-134.

Silvera, D. A. \& Austad, B. 2004, 'Factors predicting the effectiveness of celebrity endorsement advertisements,' European Journal of Marketing, Vol. 35, No. 11/12, pp. 1509-1526.

Spry, A., Pappu, R. \& Cornwell, T. B. 2011, 'Celebrity endorsement, brand credibility and brand equity,' European Journal of Marketing, Vol. 45, No. 6, pp. 882-909.

Till, B. D. \& Busler, M. 1998, 'Matching products with endorsers: attractiveness versus expertise,' Journal of Consumer Marketing, Vol. 15, No. 6, pp. 576-586.

Till, B. D. \& Busler, M. 2000, 'The Match-up Hypothesis: Physical Attractiveness, Expertise, and the Role of Fit on Brand Attitude, Purchase Intent and Brand Beliefs,' Journal of Advertising, Vol. 29, No. 3, pp. 1-13.

Till, B. D., Stanley, S. M. \& Priluck, R. 2008, 'Classical conditioning and celebrity endorsers: An examination of belongingness and resistance to extinction,' Psychology and Marketing, Vol. 25, No. 2, pp. 179-196.

Tripp, C., Jensen, T. D. \& Carlson, L. 1994, 'The Effects of Multiple Product Endorsements by Celebrities on Consumers' Attitudes and Intentions,' Journal of Consumer Research, pp. 535-547.

42 January $2012 \quad$ Volume $10 \quad$ Number $1 \quad$ Journal of Independent Studies and Research - MSSE 